Postprint Version 1.0

Journal website $\quad$ http://www.sciencedirect.com

Pubmed link http://www.ncbi.nlm.nih.gov/entrez/query.fcgi?cmd=Retrieve\&db=pubmed\&dop

DOI $\underline{\mathrm{t}=\text { Abstract\&list uids=12422319\&query } \mathrm{hl}=6 \& \text { itool=pubmed docsum }}$ 10.1053/apmr.2002.35099

From the Departments of Rehabilitation (Cardol, Beelen, de Jong, de Groot), of Clinical Epidemiology and Biostatistics (de Haan), and of Social Medicine (van den Bos), Academic Medical Center, University of Amsterdam, Amsterdam; and National Institute for Public Health and the Environment, Department of Health Services Research, Bilthoven (van den Bos), The Netherlands.

Supported in part by the Albert Heijn Trust Fund.

No commercial party having a direct financial interest in the results of the research supporting this article has or will confer a benefit upon the author(s) or upon any organization with which the author(s) is/are associated.

Correspondence to Mieke Cardol, OT, PhD, Nivel Netherlands Institute for Health Services Research, PO Box 1568, 3500 BN Utrecht, The Netherlands, e-mail: m.cardol@nivel.nl. Reprints are not available.

\title{
Responsiveness of the Impact on Participation and Autonomy Questionnaire
}

Mieke Cardol, ot, PhD, Anita Beelen, PhD, Geertrudis A. van den Bos, PhD, Bareld A. De Jong, MD, PhD, ImELDA J. DE GROOT, MD, PHD, RoB J. DE HAAN, RN, PHD

\begin{abstract}
Objective: To evaluate the responsiveness of a newly developed generic questionnaire, the Impact on Participation and Autonomy (IPA), which focuses on 2 aspects of participation: perceived participation and the experience of problems.

Design: Preliminary study of questionnaire responsiveness compared with transition indices. Participants completed 2 assessments, 3 months apart. To measure change, they completed 9 transition indices at the second assessment. One transition index assessed perceived change in general, the other 8 addressed 1 of the specific problem experience items in the IPA.
\end{abstract}

Setting: Outpatient clinic of the rehabilitation department of an academic hospital.

Participants: Fifty-seven consecutive persons admitted for multidisciplinary rehabilitation treatment, with various diagnoses, were enrolled in the study; 49 persons completed both assessments.

Interventions: Not applicable.

Main Outcome Measures: Standardized response mean (SRM) and area under the receiver operating characteristic curve (AUC) for participation domain scores and problem scores.

Results: SRMs and AUCs for the participation domains ranged from 0.1 to 1.3 and from $50 \%$ to $92 \%$, respectively. The SRMs of the items on the experience of problems ranged from 0.4 to 1.5, whereas their AUCs ranged from $56 \%$ to $74 \%$.

Conclusions: The IPA detected within-person improvement over time, but its responsiveness must be confirmed in a larger study sample. 
Outcome assessment is required to determine whether treatment has been effective (ie, whether the desired goals have been achieved). Rehabilitation treatment ultimately aims at maximizing the participation and autonomy of an individual with a disability. To obtain insight into the impact of a disease or disability on a person's life, assessment from the patient's point of view is essential because the patient's assessment will differ from that of outsiders. Because a person with a chronic disabling condition faces the consequences of that illness or disability for the rest of his/her life, rehabilitation assessment should address long-term outcomes in terms of participation. ${ }^{1}$

In a previously conducted literature study, ${ }^{2}$ we discovered that none of the few questionnaires currently available are suitable for assessing participation from the patient's point of view. For that reason, the Impact on Participation and Autonomy (IPA) questionnaire was developed to assess (1) the severity of restrictions in participation and (2) individual needs related to participation and autonomy. Items contained in the IPA are considered to be person perceived because they address the personal context, valuation, and needs of the respondent. The IPA is a generic questionnaire that addresses 2 different aspects of participation: (1) perceived participation, reflected in 31 items in 5 domains, and (2) the experience of problems for every aspect of participation, reflected in 8 problem experience scores (see appendix 1).

The clinimetric properties of an instrument must be known before the instrument can be applied in rehabilitation practice or research. The reliability and validity of the IPA are good., ${ }^{3,4}$ As yet, the use of the IPA as an instrument for outcome measure, as reflected in the concept of responsiveness, has not been studied. Responsiveness is defined as an instrument's ability to detect a clinically important change, if present, within an individual over time ${ }^{5,6}$ So, the objective of the present study was to evaluate the responsiveness of the IPA in a population of outpatients receiving multidisciplinary rehabilitation treatment.

The reliability and validity of most outcome instruments have been thoroughly analyzed, but their clinimetric value in terms of responsiveness often remains unknown. From several studies, however, including those available in the field of rehabilitation, it is clear that responsiveness is a complex feature. Several strategies have been developed to evaluate it. ${ }^{6-10}$ Different responsiveness indices provide different results, but even when the same indicators are used, the responsiveness of wellknown instruments like the Sickness Impact Profile or the Medical Outcomes Study 36-Item ShortForm Health Survey differs considerably among studies. ${ }^{11-18}$ This suggests that responsiveness is highly influenced by methodologic factors (size of the study population, time between measurements, diagnosis, characteristics of the study population) and the actual change in the phenomenon under study. Perhaps the most common method to determine an instrument's responsiveness is to compare scores of the instrument under study before and after a treatment of known efficacy. ${ }^{6,7}$ Because the efficacy of rehabilitation treatment aimed at optimizing autonomy and participation has not yet been proved, the present study used external standards to measure change (transition indices).

\section{METHODS}

\section{Study Population}

Consecutive persons who were referred for treatment to the outpatient clinic of the rehabilitation department of an academic hospital were included. Treatment was based on a multidisciplinary approach; in addition to a rehabilitation physician, the following disciplines could be involved: physical therapy, occupational therapy, speech therapy, and social work. Excluded were persons with insufficient command of the Dutch language and persons younger than 18 years of age.

\section{Methods}

Respondents were invited to take part in 2 assessments, 3 months apart. At the beginning of the first treatment session, patients were provided with both oral and written information about the study. Those who were interested could take home an envelope including a form to be signed for informed consent, a stamped addressed envelope, and the IPA. If they wished to participate in the study, respondents were requested to return the signed informed consent form and the completed IPA to the investigator (MC) by mail within 1 week. The second assessment took place after 3 months, when the IPA was sent to the person's home. To measure change, the participants were also requested to fill in 9 transition indices. Transition indices are a useful external standard against which to compare change 
scores on health status instruments. ${ }^{19}$ All transition indices consisted of a 1-item question with a 7point ordinal scale ("With regard to your ... do you feel that you are much better, better, slightly better, the same, slightly worse, worse, much worse?”). Change was defined as “(much) worse” or "(much) better." One transition index concerned perceived change in general. To obtain more explicit information on change, the other 8 indices concerned the specific aspects of participation as measured by the IPA items on the experience of problems.

\section{Statistical Analyses}

Perceived participation scores and problem scores were summarized by using descriptive statistics. We also analyzed the participation domain scores in relation to the response to the general transition index; the experience of problems was analyzed in relation to transition indices addressing the corresponding topics. Confidence intervals (CIs) for the change scores were calculated. To provide insight into the shift in the experience of problems from baseline to follow-up, the problem scores were described by percentages instead of mean scores.

Furthermore, we used the standardized response mean (SRM) to express the responsiveness to improvement. Just like the effect size, the SRM uses the mean observed change as the numerator but divides it by the standard deviation (SD) of the changed score. ${ }^{20,21}$ The criteria proposed by Cohen ${ }^{22}$ were used to interpret the SRMs, where an SRM of .20 is considered to be small, an SRM of .50 indicates moderate responsiveness, and an SRM of .80 indicates substantial responsiveness. ${ }^{22,23}$

Finally, receiver operating characteristic (ROC) curves were used, and the area under the curve (AUC) was calculated to analyze the IPA's ability to detect improvement according to an external criterion (the transition indices). ${ }^{9,24}$ Measurement scales can be viewed as diagnostic tests for discriminating between improved and unimproved patients. ${ }^{9}$ With this perspective, there will be truepositive and false-positive changes in IPA scores over time. The ROC curve depicts the truepositive rate (sensitivity) and false-positive rate (1 - specificity). The area under the ROC curve represents the probability of correctly identifying the improved patient ("much better" and "better" on the transition index) from randomly selected pairs of improved and unimproved patients. ${ }^{25}$ An AUC of $50 \%$ would mean that the IPA does not perform any better than chance, whereas an AUC of $100 \%$ represents perfect accuracy in distinguishing improved from unimproved. ${ }^{9}$

\section{RESULTS}

Fifty-seven persons were enrolled in the study. Of those, 8 were lost to follow-up: 4 developed health problems after the first measurement, 1 person moved abroad, 2 withdrew because they were emotionally overburdened, and 1 withdrew because the treatment had mainly consisted of evaluation. This attribution resulted in 49 participants in the follow-up assessment (36 women, 13 men; mean age $\pm \mathrm{SD}, 50.0 \pm 14.6 \mathrm{y})$. There were no significant differences in patient characteristics in terms of age, gender, or duration of disease between the participants and the 8 persons who were lost to follow-up. The diagnoses varied: in general, the participants suffered from chronic diseases such as neuromuscular disorders $(n=13)$, stroke $(n=8)$, hand injuries $(n=15)$, and rheumatoid disorders $(n=7)$. The median duration of the disease was 2 years (range, $0-60 \mathrm{y})$, and most respondents $(\mathrm{n}=40)$ were referred to both occupational therapy and physical therapy. After 3 months, at the time of follow-up, almost $50 \%$ of the respondents had finished their treatment.

Table 1 presents the mean participation domain scores at baseline and at follow-up with corresponding change scores and CIs for the total population. The mean change scores indicated small improvement in participation in 3 of 5 domains (family role, autonomy outdoors, work and education), but the CIs showed no significant improvement (table 1).

\section{[ TABLE 1$]$}

Table 2 shows the percentage of respondents experiencing severe and minor problems at baseline and at follow-up and their corresponding change scores. Fewer respondents recorded severe problems at follow-up with regard to mobility, family role, and work. In 3 other items, the percentage of respondents who experienced severe problems increased, especially with regard to education and 
training (table 2). This table also shows changes in the percentages of perceived minor problems; at follow-up, fewer respondents perceived problems, especially in the item on leisure.

\section{[ TABLE 2 ]}

After 3 months, 30 respondents (61\%) indicated no perceived change on the general transition index. This finding was also reflected in their mean change scores per domain (range, -0.8 to 0.0; SD, 1.24.0) Two respondents, diagnosed with amyotrophic lateral sclerosis and postpoliomyelitis syndrome, respectively, indicated deterioration on the general transition index, and this is reflected in their IPA scores: mean change score \pm SD for autonomy indoors, $-7.5 \pm 2.1$; for family role, $-6.5 \pm 6.4$; for autonomy outdoors, $-4.0 \pm 1.4$; and for social relations, $-2.5 \pm 3.5$. The items in the domain of work and education were not applicable to either of these respondents.

In tables 3 and 4, SRMs and AUCs for improvement in the participation domains and experience of problems are presented. Both indicators yielded the same results: table 3 shows responsiveness to improvement in the domains of work and education, autonomy outdoors, and family role but no responsiveness in the domains of autonomy indoors and social relations. When using a problemspecific transition index, both the SRM and the AUC for social relations indicated more responsiveness (table 4). In general, the responsiveness of the items on the experience of problems was lower compared with the participation domains. Mobility and financial situation showed the smallest SRMs and AUCs (table 4).

\section{[ TABLE 3 ] \\ [ TABLE 4 ]}

\section{DISCUSSION}

When evaluating rehabilitation interventions, responsiveness is a crucial property of an outcome measurement instrument. ${ }^{26}$ The results of the present study show that the IPA detects within-person improvement over time. With regard to the participation domains, autonomy indoors and social relations were less responsive than the other domains, whereas the general responsiveness of the items on the experience of problems was moderate. Surprisingly, mobility, the most concrete item, was the most insensitive in detecting improvement.

Because only 2 respondents perceived a decline in participation, we could not investigate the IPA's responsiveness with regard to deterioration. Moreover, the study sample was small, which implies that the IPA's responsiveness must be confirmed in a larger study population. The present study should be considered as preliminary. Nevertheless, because the responsiveness of disease-specific measures is generally superior to that of generic measures, ${ }^{27-31}$ the IPA seems to be a promising generic scale for severity and outcome assessment.

Some remarks can be made concerning the methodology of our study. Although a transition index is a useful alternative when a treatment of known efficacy is missing, Norman et al ${ }^{32}$ questioned the use of retrospective transition ratings, not only because the reliability and validity of transition indices are difficult to verify but also because judgment of change is psychologically difficult. Patients must be able to quantify both their present state and their initial state and then perform a mental subtraction. As suggested by Guyatt et $\mathrm{al},{ }^{33}$ a solution for this dilemma can be to show patients their previous responses. Furthermore, when measuring change, one presumes that the point of reference is fixed, that is, that an individual's attitude toward illness and participation will remain stable. ${ }^{34}$ However, attitudes are not constant; they vary with time and experience and are modified by coping, adaptation, recent experiences, or hope (also known as response shift ${ }^{35,36}$ ). This is especially the case during rehabilitation treatment, when people have to find new strategies to adapt to their illness. The use of clinician judgment of change is not likely to avoid this bias because the clinician must use the patient as informant. ${ }^{32}$ Related to this, in the present study, the therapists also completed transition indices. Comparing the transition indices of the patients and their therapists, we found significant differences, even concerning seemingly unambiguous aspects such as mobility or self-care. The therapists indicated that they sometimes found it difficult to fill in the transition indices. They felt that the patient 
had improved, but they could not translate this into concrete transition scores. Clearly, rehabilitation treatment is multidimensional, and possible effects cannot be shown by the appraisal of only 1 entity. Considering these issues, one may conclude that consensus on the best method to evaluate the responsiveness of a measure has not yet crystallized. Probably, our method to evaluate the responsiveness of the IPA was less than ideal; however, no (acknowledged) best method exists as yet. Finally, as shown in tables 1 and 2, perceived participation differs from the experience of a problem, and consequently the change scores for both features are not necessarily the same. Despite treatment, the experience of problems may even increase in some respects because of increased awareness of the consequences of the disease. In the present study, $61 \%$ of the respondents reported no change on the general transition index. Reasons for this finding may relate to the composition of the study sample (improvement in chronic illness may be more difficult to achieve than improvement in acute or reversible conditions), to the waiting period for adaptations, or to the generality of the transition index. It could also be argued that a follow-up of 3 months is too short to show responsiveness, especially for an instrument to assess autonomy and participation. However, almost $50 \%$ of the respondents received treatment for less than 3 months, and maybe a treatment period of 3 months can be considered long enough to evaluate whether the treatment addressed the right issues. This gives rise to an important question: What constitutes a relevant change? A statistically significant change over time need not be similar to what the patient considers to be a relevant change.

\section{CONCLUSION}

The scores on the IPA items addressing the experience of problems may be the optimum outcome measure for change because they reflect the patient's opinion of the relevant issues and desired effects of treatment. More research is needed on the IPA items that address the patient's experience of problems because in the present study these items appeared to be somewhat less sensitive to change than the IPA's participation domains.

\section{TABLES AND APPENDIX}

\begin{tabular}{|c|c|c|c|c|}
\hline Domains of the IPA & $\begin{array}{l}\text { Baseline } \\
\text { Score }\end{array}$ & $\begin{array}{l}\text { Follow-Up } \\
\text { Score }\end{array}$ & $\begin{array}{l}\text { Change } \\
\text { Score* }\end{array}$ & $\begin{array}{c}95 \% \mathrm{Cl} \\
\text { Change Score }\end{array}$ \\
\hline Autonomy indoors & $15.5 \pm 5.6$ & $15.4 \pm 5.6$ & $0.1 \pm 3.8$ & -0.9 to 1.3 \\
\hline Family role & $21.0 \pm 6.6$ & $20.0 \pm 7.0$ & $0.9 \pm 5.4$ & -0.8 to 2.4 \\
\hline Autonomy outdoors & $14.7 \pm 4.6$ & $14.1 \pm 5.3$ & $0.6 \pm 2.6$ & -0.1 to 1.4 \\
\hline Social relations & $13.8 \pm 4.1$ & $13.8 \pm 4.7$ & $0.0 \pm 3.2$ & -0.9 to 0.9 \\
\hline Work and education & $16.4 \pm 5.2$ & $15.9 \pm 5.9$ & $0.5 \pm 1.8$ & -0.7 to 1.3 \\
\hline
\end{tabular}

* Change score is the baseline score minus score at follow-up.

Table 2: Percentage of Respondents Experiencing Problems at Baseline and at Follow-Up With Corresponding Change Scores* ( $\mathrm{N}=49$ )

\begin{tabular}{|c|c|c|c|c|c|c|c|c|}
\hline $\begin{array}{c}\text { IPA Items on } \\
\text { Problem Experience }\end{array}$ & Mobility & Self-Care & Family Role & $\begin{array}{l}\text { Financial } \\
\text { Situation }\end{array}$ & Leisure & $\begin{array}{c}\text { Social } \\
\text { Relations }\end{array}$ & Work & $\begin{array}{l}\text { Education } \\
\text { and Training }\end{array}$ \\
\hline \multicolumn{9}{|l|}{ At baseline } \\
\hline Severe problem & 18 & 9 & 28 & 12 & 25 & 14 & 54 & 16 \\
\hline Minor problem & 63 & 51 & 53 & 25 & 60 & 39 & 31 & 34 \\
\hline \multicolumn{9}{|l|}{ At follow-up } \\
\hline Severe problem & 14 & 8 & 22 & 12 & 34 & 18 & 28 & 29 \\
\hline Minor problem & 56 & 50 & 56 & 26 & 42 & 40 & 44 & 41 \\
\hline \multicolumn{9}{|l|}{ Percentage of change } \\
\hline Severe problem & 4 & 1 & 6 & 0 & -9 & -4 & 26 & -13 \\
\hline Minor problem & 7 & 1 & -3 & -1 & 18 & -1 & -13 & -7 \\
\hline
\end{tabular}

NOTE. All values are percentages.

* Change score is the baseline score minus the score at follow-up. 
Cardol, M., Beelen, A., Bos, G.A. van den, Jong, B.A. de, Groot, I.J. de, Haan, R.J. de

Responsiveness of the impact on participation and autonomy questionnaire.

Archives of Physical Medicine and Rehabilitation: 2002, nr. 83, p. 1524-1529

Table 3: Mean Change Scores for Improvement $(n=17)$ and Responsiveness to Improvement of the IPA Participation Domains Expressed in SRM and AUC

\begin{tabular}{|c|c|c|c|c|}
\hline Participation Domains IPA & Change Score for Improvement* \pm SD & $95 \% \mathrm{Cl}$ & $\mathrm{SRM}^{\dagger}$ & $\operatorname{AUC}(\%)^{\ddagger}$ \\
\hline Autonomy indoors & $1.4 \pm 3.3$ & -0.3 to 3.1 & 0.4 & 62 \\
\hline Family role & $3.9 \pm 4.9$ & $1.4-6.4$ & 0.8 & 80 \\
\hline Autonomy outdoors & $2.7 \pm 2.2$ & $1.6-3.8$ & 1.2 & 89 \\
\hline Social relations & $0.2 \pm 2.8$ & -1.2 to 1.6 & 0.1 & 50 \\
\hline Work and education ( $\mathrm{n}=5$ persons improved) & $2.0 \pm 1.5$ & $0.1-3.9$ & 1.3 & 92 \\
\hline
\end{tabular}

* Related to improvement as indicated by the general transition index ( $n=17$, except for the domain work and education), range of score for items on participation: 7-35 (autonomy indoors, family role), 5-25 (autonomy outdoors), and 6-30 (social relations, work and education).

t For the improved group $(n=17)$.

₹ Improvement $(n=17)$ versus no improvement $(n=32)$.

Table 4: Mean Change Scores for Improvement and Responsiveness to Improvement of the IPA Items on the Experience of Problems Expressed in SRM and AUC

\begin{tabular}{|c|c|c|c|c|c|}
\hline $\begin{array}{l}\text { IPA Items on Problem } \\
\text { Experience }\end{array}$ & $\begin{array}{l}\text { Change Score for } \\
\text { Improvement* } \pm \text { SD }\end{array}$ & $\begin{array}{c}\text { Persons } \\
\text { Improved (n) }\end{array}$ & $95 \% \mathrm{Cl}$ & $\mathrm{SRM}^{+}$ & $\operatorname{AUC}(\%)^{\ddagger}$ \\
\hline Mobility & $0.3 \pm 0.6$ & 16 & -0.0 to 0.6 & 0.5 & 56 \\
\hline Self-care & $0.4 \pm 0.5$ & 13 & -0.1 to 0.7 & 0.7 & 69 \\
\hline Family role & $0.4 \pm 0.5$ & 12 & -0.1 to 0.7 & 0.8 & 61 \\
\hline Financial situation & $0.2 \pm 0.4$ & 6 & -0.2 to 0.6 & 0.4 & 58 \\
\hline Leisure & $0.6 \pm 0.5$ & 11 & $0.3-0.9$ & 1.2 & 74 \\
\hline Social relations & $0.6 \pm 0.5$ & 5 & -0.0 to 1.2 & 0.7 & 71 \\
\hline Work & $0.8 \pm 0.5$ & 4 & $0.1-1.6$ & 1.5 & 71 \\
\hline Education and training & - & 0 & - & - & - \\
\hline
\end{tabular}

* Related to improvement as indicated by the transition index of corresponding subject, mean scores \pm SD; range of score for items on problem experience: $0-2$.

For the persons improved.

‡Improvement versus no improvement.

APPENDIX 1: THE IMPACT ON PARTICIPATION AND AUTONOMY QUESTIONNAIRE*

Response options per item: very good, good, fair, poor, very poor. Response options for problem experience: no problems, minor problems, severe problems.

\section{Autonomy indoors $(\mathrm{n}=7)$}

In the context of illness or disability. .

1. My chances of getting around in my house where I want to are

2. My chances of getting around in my house when I want to are

3. My chances of washing, dressing, and grooming the way I wish are

4. My chances of washing, dressing, and grooming when I want to are

5. My chances of getting up and going to bed when I want to are

6. My chances of going to the toilet when I wish and need to are

7. My chances of deciding when I want to eat and drink are

Family role $(n=7)$

In the context of illness or disability...

1. My chances of contributing to looking after my home the way I want to are

2. My chances of getting minor housework jobs done (eg, cooking, making tea or coffee), either by myself or by someone else, the way I want them done are

3. My chances of getting heavy housework jobs done (eg, cleaning), either by myself or by others, the way I want them done are

4. My chances of getting housework done, either by myself or by others, when I want them done are

5. My chances of getting minor repairs and maintenance work done in my house, either by myself or by others, the way I want them done are

6. My chances of fulfilling my role at home as I would like are

7. My chances of spending my own money as I wish are 
Cardol, M., Beelen, A., Bos, G.A. van den, Jong, B.A. de, Groot, I.J. de, Haan, R.J. de Responsiveness of the impact on participation and autonomy questionnaire.

Archives of Physical Medicine and Rehabilitation: 2002, nr. 83, p. 1524-1529

APPENDIX 1 (CONT'D): THE IMPACT ON PARTICIPATION AND AUTONOMY QUESTIONNAIRE*

Response options per item: very good, good, fair, poor, very poor. Response options for problem experience: no problems, minor problems, severe problems.

Autonomy outdoors $(\mathrm{n}=5)$

In the context of illness or disability. .

1. My chances of visiting relatives and friends when I want to are

2. My chances of going on the sort of trips and holidays I want to go on are

3. My chances of seeing people as often as I want are

4. My chances of living life the way I want are

5. My chances of spending leisure time the way I want to are

Social relations $(n=6)$

In the context of illness or disability. .

1. My chances of talking to people close to me on equal terms are

2. The quality of my relationship with people who are close to me is

3. The respect I receive from people who are close to me is

4. My relationships with acquaintances are

5. The respect I receive from acquaintances is

6. My chances of having an intimate relationship are

Work and education $(n=6)$

In the context of illness or disability. .

1. My chances of doing the work or occupation I want to do are

2. My chances of doing my work the way I want to are

3. My contacts with my colleagues are

4. My chances of achieving or maintaining the job I want are

5. My chances of getting a different job with the same or different employer are

6. My chances of getting the training or education I want are

Items addressing problem experience $(n=8)$

1. With regard to your indoor and outdoor mobility, to what extent does your illness or disability cause problems?

2. With regard to your self-care, to what extent does your illness or disability cause problems?

3. With regard to your family role, to what extent does your illness or disability cause problems?

4. With regard to controlling your finances, to what extent does your illness or disability cause problems?

5. With regard to your leisure time, to what extent does your illness or disability cause problems?

6. With regard to your relationships, to what extent does your illness or disability cause problems?

7. With regard to your occupation, to what extent does your illness or disability cause problems?

8. With regard to your education or learning, to what extent does your illness or disability cause problems?

* Official English version (IPA-E), resulting from a forward-backward translation.

\section{REFERENCES}

1. World Health Organization. ICIDH-2: International classification of functioning and disability. Beta-2 draft, full version. Geneva: WHO; 1999.

2. Cardol M, Brandsma JW, de Groot IJ, van den Bos GA, de Haan RJ, de Jong BA. Handicap questionnaires: what do they assess? Disabil Rehabil 1999;21:97-105.

3. Cardol M, de Haan RJ, van den Bos GA, de Jong BA, de Groot IJ. The development of a handicap assessment questionnaire: the Impact on Participation and Autonomy (IPA). Clin Rehabil 1999; 13:411-9.

4. Cardol M, de Haan RJ, de Jong BA, van den Bos GA, de Groot IJ. Psychometric properties of the questionnaire Impact on Participation and Autonomy. Arch Phys Med Rehabil 2001;82:210-6.

5. Kirshner B, Guyatt G. A methodological framework for assessing health indices. J Chronic Dis 1985;38:27-36.

6. Deyo RA, Diehr P, Patrick DL. Reproducibility and responsiveness of health status measures. Control Clin Trials 1991;12(4 Suppl):142S-58S.

7. Guyatt G, Walter S, Norman G. Measuring change over time: assessing the usefulness of evaluative instruments. J Chronic Dis 1987;40:171-8.

8. Kazis LE, Anderson JJ, Meenan RF. Effect sizes for interpreting changes in health status. Med Care 1989;27(3 Suppl):S178-89.

9. Deyo RA, Centor RM. Assessing the responsiveness of functional scales to clinical change: an analogy to diagnostic test performance. J Chronic Dis 1986;39:897-906.

10. Guyatt GH, Deyo RA, Charlson M, Levine MN, Mitchell A. Responsiveness and validity in health status measurement: a clarification. J Clin Epidemiol 1989;42:403-8.

11. Freeman JA, Hobart JC, Langdon DW, Thompson AJ. Clinical appropriateness: a key factor in outcome measure selection: the 36 item short form health survey in multiple sclerosis. $\mathrm{J}$ Neurol Neurosurg Psychiatry 2000;68:150-6.

12. Jacoby A, Baker GA, Steen N, Buck D. The SF-36 as a health status measure for epilepsy: a psychometric assessment. Qual Life Res 1999;8:351-64.

13. Taylor SJ, Taylor AE, Foy MA, Fogg AJB. Responsiveness of common outcome measures for patients with low back pain. Spine 1999;24:1805-12. 
14. Beaton DE, Hogg-Johnson S, Bombardier C. Evaluating changes in health status: reliability and responsiveness of five generic health status measures in workers with musculoskeletal disorders. J Clin Epidemiol 1997;50:79-93.

15. Harper R, Brazier JE, Waterhouse JC, Walters SJ, Jones NM, Howard P. Comparison of outcome measures for patients with chronic obstructive pulmonary disease (COPD) in an outpatient setting. Thorax 1997;52:879-87.

16. MacKenzie CR, Charlson ME, DiGioia D, Kelley K. Can the Sickness Impact Profile measure change? An example of scale assessment. J Chronic Dis 1986;39:429-38.

17. Jacobs HM, Touw-Otten FW, de Melker RA. The evaluation of changes in functional health status in patients with abdominal complaints. J Clin Epidemiol 1996;2:163-71.

18. Damiano AM, Patrick DL, Guzman GI, et al. Measurement of healthrelated quality of life in patients with amyotrophic lateral sclerosis in clinical trials of new therapies. Med Care 1999;37:15-26.

19. Deyo R, Inui T. Toward clinical applications of health status measures: sensitivity of scales to clinically important changes. Health Serv Res 1984;19:275-89.

20. Liang MH, Fossel AH, Larson MG. Comparisons of five health status instruments for orthopedic evaluation. Med Care 1990;28: 632-42.

21. Katz JN, Larson MG, Phillips CB, Fossel AH, Liang MH. Comparative measurement sensitivity of short and longer health status instruments. Med Care 1992;30:917-25.

22. Cohen J. Statistical power analysis for the behavioral sciences. New York: Academic Pr; 1977.

23. Meenan R, Kazis L, Anthony J, Wallin B. The clinical and health status of patients with recent onset rheumatoid arthritis. Arthritis Rheum 1991;34:761-5.

24. Sackett DL, Haynes RB, Guyatt GH, Tugwell P. Clinical epidemiology. A basic science for clinical medicine. Boston: Little, Brown; 1991.

25. Hanley JA, McNeil BJ. The meaning and use of the area under a receiver operating characteristic (ROC) curve. Radiology 1982; 143:29-36.

26. Fitzpatrick R, Ziebland S, Jenkinson C, Mowat A, Mowat A. Importance of sensitivity to change as a criterion for selecting heath status measures. Qual Health Care 1992;1:89-93.

27. Stucki G, Liang MH, Fossel AH, Katz JN. Relative responsiveness of condition-specific and generic health status measures in degenerative lumbar spinal stenosis. J Clin Epidemiol 1995;48: 1369-78.

28. Bessette L, Sangha O, Kuntz KM, et al. Comparative responsiveness of generic versus disease-specific and weighted versus unweighted health status measures in carpal tunnel syndrome. Med Care 1998;36:491-502.

29. Birbeck GL, Kim S, Hays RD, Vickrey BG. Quality of life measures in epilepsy. Neurology 2000;54:1822-7.

30. Wright JG, Young NL. A comparison of different indices of responsiveness. J Clin Epidemiol 1997;50:239-46.

31. Garratt AM, Ruta DA, Abdalla MI, Russell IT. Responsiveness of the SF-36 and a conditionspecific measure of health for patients with varicose veins. Qual Life Res 1996;5:223-34.

32. Norman GR, Stratford P, Regehr G. Methodological problems in the retrospective computation of responsiveness to change: the lesson of Cronbach. J Clin Epidemiol 1997;50:869-79.

33. Guyatt GH, Berman LB, Townsend M, Taylor DW. Should study subjects see their previous responses? J Chronic Dis 1985;38: 1003-7.

34. Allison PJ, Locker D, Feine JS. Quality of life: a dynamic construct. Soc Sci Med 1997;45:22130.

35. Sprangers MA, Schwartz CE. Integrating response shift into health related quality of life research: a theoretical model. Soc Sci Med 1999;48:1507-15.

36. Wilson IB. Clinical understanding and clinical implications of response shift. Soc Sci Med 1999;48:1577-88. 